\title{
Fields-Backofen and a Modified Johnson-Cook Model for CP-Ti at Ambient and Intermediate Temperature
}

\author{
Chang Le, Zhou Changyu, Peng Jian, Li Jian, He Xiaohua
}

Nanjing Tech University, Nanjing 211816, China

\begin{abstract}
The flow stress behavior of commercial pure titanium (CP-Ti) was studied by uniaxial tension tests at temperatures ranging from 283 to $573 \mathrm{~K}$ and strain rates from $0.00005 \sim 0.005 \mathrm{~s}^{-1}$. The tensile properties of CP-Ti was investigated to determine the quantitative variation of the strain rate sensitivity and the strain hardening with temperature. The results show that the strain rate sensitivity of $\mathrm{CP}-\mathrm{Ti}$ at $283 \sim 423 \mathrm{~K}$ is not obvious and strain hardening index increases with temperature at $353 \sim 573 \mathrm{~K}$. A mathematical model using an updated Fields-Backofen (FB) equation based on temperature changing was established to describe the plastic flow stress behavior of CP-Ti. Meanwhile by considering the coupled effects of strain, strain rate and temperature, a modified Johnson-Cook (JC) model were proposed to predict the flow behavior. Compared with the original JC model, the modified JC model shows better agreement with the experimental stress, which validates the accuracy of the modified model describing the plastic flow stress of CP-Ti.
\end{abstract}

Key words: commercial pure titanium; tensile deformation; Fields-Backofen model; Johnson-Cook model

Commercial pure Titanium (CP-Ti) is attractive material for its good properties such as high strength, high specific work hardening ability, excellent plasticity, toughness, corrosion resistance and weld ability ${ }^{[1]}$. Fully understanding the mechanical properties of CP-Ti is a foundation of titanium equipment design and manufacture. At present, many studies discuss the relationship between microstructure and macro flow stress based on the Arrhenius model at different temperatures and strain rates ${ }^{[2-5]}$. Obviously, the strain rate sensitivity and strain hardening is affected by temperature ${ }^{[6,7]}$; however, the coupled effects of the strain rate sensitivity, the strain hardening and the temperature on the flow stress of $\mathrm{CP}-\mathrm{Ti}$ is not clear. Meanwhile on a macroscale the flow stress mathematical equation with the deformation temperature, strain rate and deformation degree as variables for $\mathrm{CP}-\mathrm{Ti}$ at ambient and intermediate temperature is less.

In the present study, uniaxial tensile tests of CP-Ti were conducted under different deformation conditions to investigate the effects of strain rate and deformation temperature on the flow behaviors.

\section{Experiment}

The material used in this investigation was CP-Ti TA2. The specimens with in $3 \mathrm{~mm}$ thickness, in 25 gauge and $6 \mathrm{~mm}$ in width were machined from the as-received plate by wire electrical discharge machining. The tensile testing was carried out by Instron tensile experimental equipment. The detailed experimental scheme is listed in Ref. [5].

\section{Results and Discussion}

Fig. 1 shows the results of the stress-strain curves for CP-Ti at different temperatures and strain rates.

It can be seen that the typical strain hardening curves can be obtained. As shown in Fig.1a and 1b, when the strain rate is certain, the plastic flow stress-strain curves decrease with temperature. On the country, the flow stress increases with strain rate when the temperature is certain, shown as Fig.1c, 1d. Therefore, it is necessary to investigate how the strain hardening and strain rate sensitivity vary with temperature. In this paper, two constitutive models viz. Fields-Backofen

Received date: July 10, 2016

Foundation item: National Natural Science Foundation of China (51475223, 51075199)

Corresponding author: Zhou Changyu, Ph. D., Professor, School of Mechanical and Power Engineering, Nanjing Tech University, Nanjing 211816, P. R. China, Tel 0086-25-58139951, E-mail: changyu_zhou@163.com 

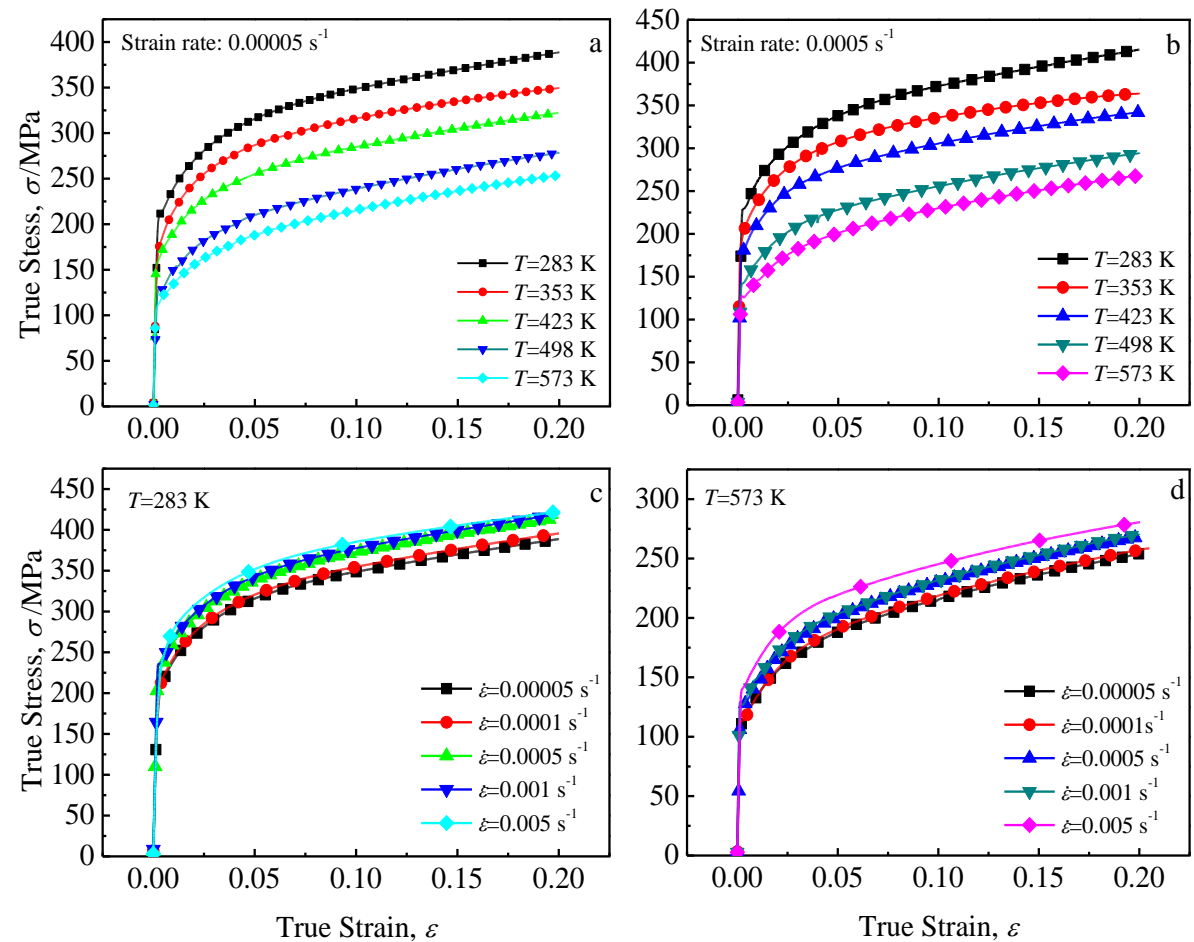

Fig.1 Typical stress-strain curves for CP-Ti at different temperatures and strain rates: (a) $\dot{\varepsilon}=0.00005 \mathrm{~s}^{-1}$, (b) $\dot{\varepsilon}=0.0005 \mathrm{~s}^{-1}$, (c) $T=283 \mathrm{~K}$, and (d) $T=573 \mathrm{~K}$

(FB) model and Johnson-cook(JC) model will be developed to describe its plastic flow behavior.

\subsection{Fields-Backofen model}

FB model, expressed as follows:

$\ln \sigma=\ln K+n \ln \varepsilon+m \ln \dot{\varepsilon}$

where, $K$ is the strength coefficient, $n$ is the strain hardening exponent, and $m$ is the strain rate sensitivity exponent.

(1) $m$-value

The relationship between true stress and strain rate in $\log$ - $\log$ scale at $423 \mathrm{~K}$ and different strains is linear as shown in Fig.2a and the slope of the stress-strain rate curve is equal to the value of the strain rate sensitivity (SRS) exponent. Using this method, $m$ at different temperatures are obtained. From Fig.2b, it can be seen that the $m$ value gradually decreases with strain increasing at 283 573 K. The decreasing tendency of $m$ value with strain has also been found in magnesium alloy AZ31, and it can be explained as the larger strain hardening at lower strain rate ${ }^{[8,9]}$. In order to obtain the influence of temperature on $m$, the curves of $m$ vs. temperature under different strains are shown in Fig.3. At relatively low temperature $(283 \sim 423 \mathrm{~K})$, the SRS of CP-Ti is not obvious, which is the common feature of alloys due to dynamic strain aging $^{[10]}$. At relatively high temperature $(423 \sim 573 \mathrm{~K})$, the increase of $m$ is the result of softening behavior caused by dynamic recovery. Based on the relationship between $m$ and strain and temperature, the equation of $m$ varies with temperature and strain can be obtained as follows:

$$
\begin{aligned}
m= & -0.01668 \log \varepsilon-4.3061 \times 10^{-7} T^{2}+ \\
& 0.000395 T-0.0733
\end{aligned}
$$

(2) $n$-value

The strain hardening exponent $n$ decreases linearly with strain rate increasing, which is shown in Fig.4. As it is known, the deformation of CP-Ti requires interactions of twins and dislocation $^{[11]}$. The amount decrease of twins at 283 353 K
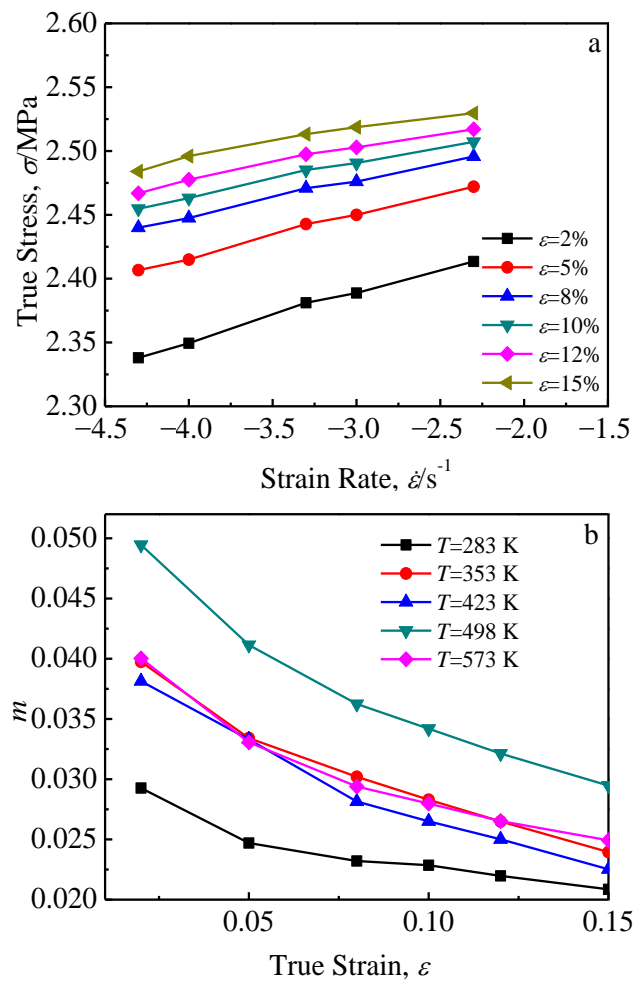

Fig.2 Relationship between $\sigma-\dot{\varepsilon}$ (a) and $m-\varepsilon$ (b) 


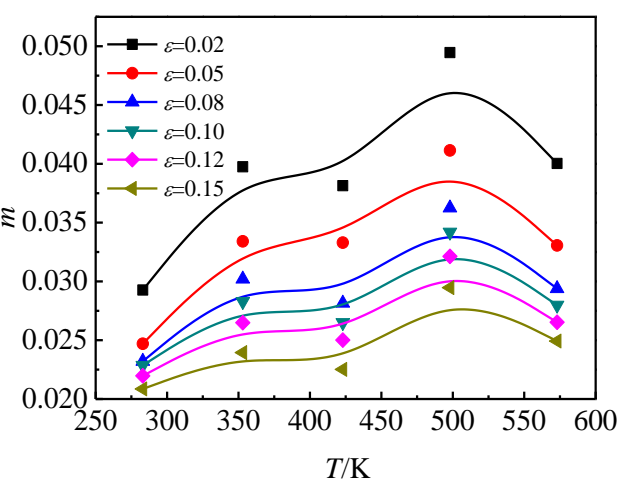

Fig.3 Relationship between $m$ and $T$

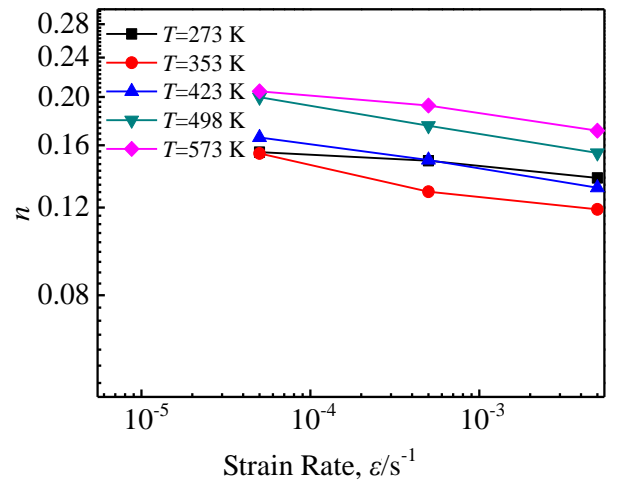

Fig.4 Relationship between $n$ and $\dot{\varepsilon}$

reduce the value of $n$ with the temperature increasing as shown in Fig.5. Liu et al. ${ }^{[12]}$ found that more slip systems will be activated as temperature increases. Therefore, the increased dislocation density as well as their interaction may be the major role of the increased $n$ at the temperature of 353 573 $\mathrm{K}^{[10]}$. According to the relationship between $n$ and strain rate and temperature, $n$ is approximately given by:

$$
\begin{aligned}
n & =-0.016637 \log \dot{\varepsilon}+0.000001 T^{2}-0.000538 T \\
& +0.173229
\end{aligned}
$$

(3) $K$-value

Fig. 6 shows the relationship between $K$ and strain, Fig.7 shows the relationship between $K$ and stain rate and Fig.8 shows the relationship between $K$ and $T^{1}$. Based on the relationship between $K$ and the strain, strain rate, temperature, the $K$-value can be expressed as the following equation:

$$
\begin{aligned}
K= & -329.304 \varepsilon-5.73142 \log \dot{\varepsilon}+99437.2 / T+ \\
& 289.3288
\end{aligned}
$$

(4) Evaluation of the constitutive equations

The comparison between the calculated results by FB equations and the experimental data at different strain rates and temperatures is shown in Fig.9. The predictability of the constitutive equation is further verified via employing standard statistical parameters. The FB model shows very high degree of goodness of fit as the correlation coefficient is above

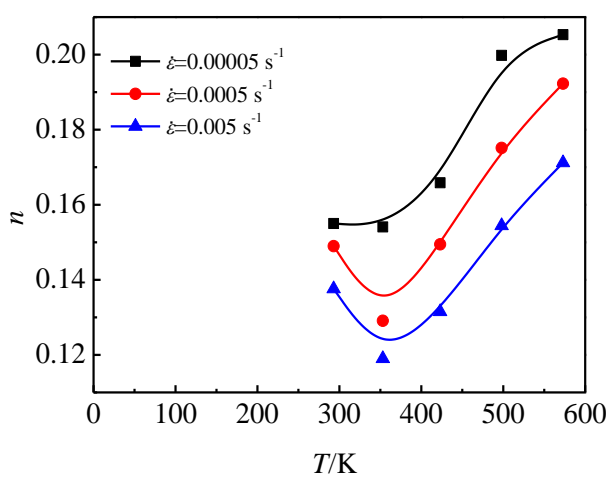

Fig.5 Relationship between $n$ and $T$

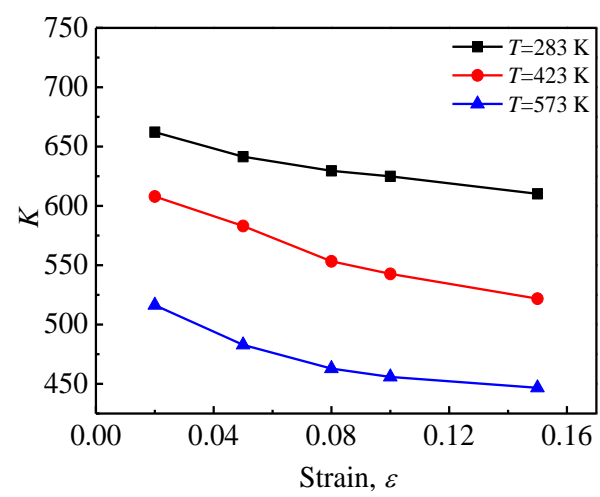

Fig.6 Relationship between $K$ and $\varepsilon$

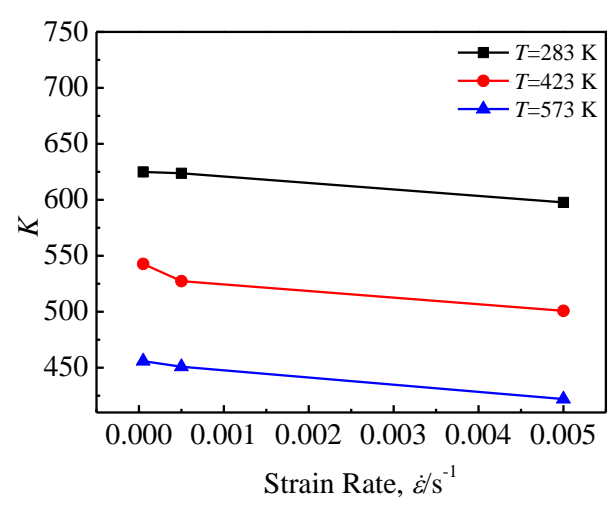

Fig.7 Relationship between $K$ and $\dot{\varepsilon}$

0.98 at different temperatures and strain rates and the mean absolute error is $4.08 \%$.

\subsection{Johnson-Cook model}

The original JC model is expressed as:

$$
\sigma=\left(A+B \varepsilon^{n}\right)\left(1+C \ln \dot{\varepsilon}^{*}\right)\left(1-T^{* m}\right)
$$

where $\sigma$ is the Von-Mises flow stress, $A$ is the yield stress at the reference temperature and reference strain rate, $B$ is the coefficient of strain hardening, $n$ is the strain hardening exponent, $\varepsilon$ is the plastic strain, $C$ and $m$ are the material constants. The original JC model could be accepted only under 


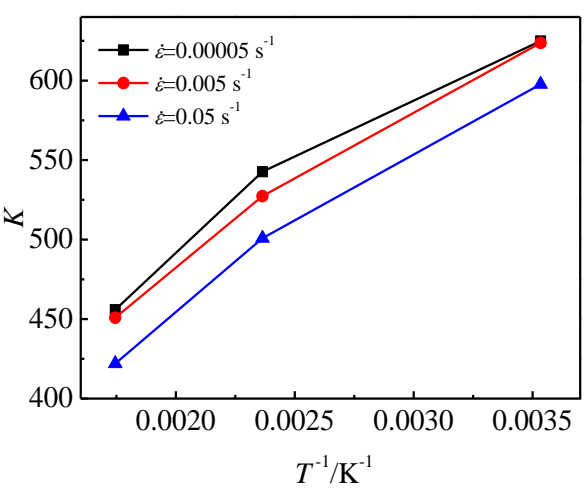

Fig.8 Relationship between $K$ and $T^{1}$
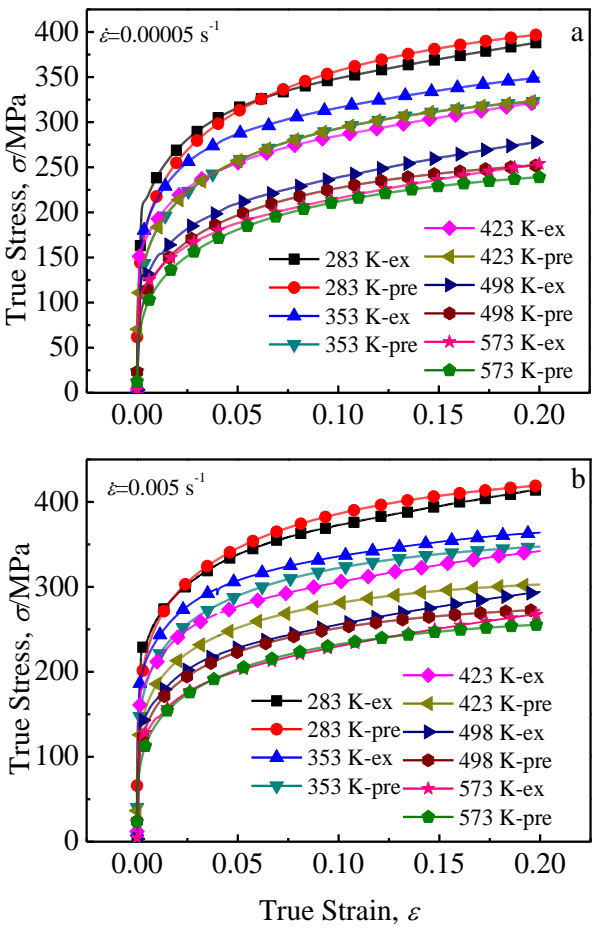

Fig.9 Comparison between the experimental value and the predicted value: (a) $\dot{\varepsilon}=0.00005 \mathrm{~s}^{-1}$ and (b) $\dot{\varepsilon}=0.005 \mathrm{~s}^{-1}$

the reference temperature and reference strain rate. This is because the original JC model assumes that thermal softening, strain rate hardening and strain hardening are three independent phenomena and can be isolated from each other. Many modified JC model have been proposed with considering the couple effects of temperature and strain rates $^{[13-15]}$. Therefore, in this section, a modified JC model will be proposed to describe the flow stress of $\mathrm{CP}-\mathrm{Ti}$ under different deformation conditions.

\subsubsection{Original JC model}

The ambient temperature $283 \mathrm{~K}$ and the strain rate $0.00005 \mathrm{~s}^{-1}$ were taken as the reference temperature and the reference strain rate respectively, and $T_{\mathrm{m}}$ was adopted as $1941 \mathrm{~K}$. The traditional JC constitutive equation is obtained as follows:

$$
\begin{aligned}
\sigma= & \left(213.89+355.8192 \varepsilon^{0.438102}\right)\left(1+0.02559 \ln \dot{\varepsilon}^{*}\right) . \\
& \left(1-T^{* 1.08}\right)
\end{aligned}
$$

\subsubsection{Modified JC model}

Considering the coupled effects of strain and temperature, and of strain rate and temperature on the flow behaviors, a modified JC model was proposed in this paper. It can be expressed as follows:

$$
\sigma=\left(A+B_{1} \varepsilon+B_{2} \varepsilon^{2}\right)\left(1+C \ln \dot{\varepsilon}^{*}\right) \exp f T^{*}
$$

Where $A, B_{1}, B_{2}, C$ are material constants, $f$ is the function of strain and strain rate, expressed as $f=f(\varepsilon, \ln \dot{\varepsilon})$, and other variables are defined as the original JC model.

(a) Calculation of the parameters $A, B_{1}$ and $B_{2}$

Like the original JC model, $283 \mathrm{~K}$ is taken as reference temperature and $0.00005 \mathrm{~s}^{-1}$ the reference strain rate to evaluate the material constants. The value of $A, B_{1}$ and $B_{2}$ can be fitted as $238.5783,1605.288$, and $-4667.36 \mathrm{MPa}$, respectively.

(b) Calculation of the parameter $C$

When the deformation temperature is $283 \mathrm{~K}$, Eq.(7) can be expressed as follows:

$$
\frac{\sigma}{\left(A+B_{1} \varepsilon+B_{2} \varepsilon^{2}\right)}=1+C \ln \dot{\varepsilon}^{*}
$$

The relationship between $\frac{\sigma}{\left(A+B_{1} \varepsilon+B_{2} \varepsilon^{2}\right)}$ and $\ln \dot{\varepsilon}^{*}$ can be obtained as linear. Then, the value of $C$ is fitted as 0.025588 .

(c) Determination of the function $f$

Taking natural logarithm of Eq.(7), Eq.(9) could be gained as follows:

$$
\ln \left[\frac{\sigma}{\left(\mathrm{A}+B_{1} \varepsilon+B_{2} \varepsilon^{2}\right)\left(1+C \ln \dot{\varepsilon}^{*}\right)}\right]=f T^{*}
$$

The relationship between $\ln \left[\sigma /\left(A+B_{1} \varepsilon+B_{2} \varepsilon^{2}\right)\left(1+C \ln \dot{\varepsilon}^{*}\right)\right]$ and $T^{*}$ can be obtained, as shown in Fig.10. It can be seen that the relationship between them is linear and the corresponding value of $f$ can be obtained. The value of $f$ is dependent on the deformation strain and strain rate. In order to obtain the relationship between $f$ and strain and strain rate, curves of $f$ - $\varepsilon$ and $f-\ln \dot{\varepsilon}^{*}$ were drawn as shown in Fig.11 and Fig.12. It can be seen that the relationship between $f$ and stain could be fitted by quartic equation from Fig.11, expressed as follows:

$$
\begin{aligned}
& f=f\left(\varepsilon, \ln \dot{\varepsilon}^{*}\right)=\left(a_{1}+a_{2} \varepsilon+a_{3} \varepsilon^{2}+a_{4} \varepsilon^{3}+a_{5} \varepsilon^{4}\right) . \\
& f_{2}\left(\ln \dot{\varepsilon}^{*}\right)
\end{aligned}
$$

From Fig.12, the linear relationship between $f$ and $\ln \dot{\varepsilon}^{*}$ can be obtained, expressed as follows:

$$
f=f\left(\varepsilon, \ln \dot{\varepsilon}^{*}\right)=f_{1}(\varepsilon)\left(a_{6} \ln \dot{\varepsilon}^{*}+a_{7}\right)
$$

According to Eq.(10) and Eq.(11), the function of $f$ containing strain and strain rate can be obtained, expressed as follows:

$$
\begin{aligned}
f=f\left(\varepsilon, \ln \dot{\varepsilon}^{*}\right)= & \left(a_{1}+a_{2} \varepsilon+a_{3} \varepsilon^{2}+a_{4} \varepsilon^{3}+\right. \\
& \left.a_{5} \varepsilon^{4}\right)\left(a_{6} \ln \dot{\varepsilon}^{*}+a^{7}\right)
\end{aligned}
$$

Substituting the values of $f$ into Eq.(12), the parameters of 

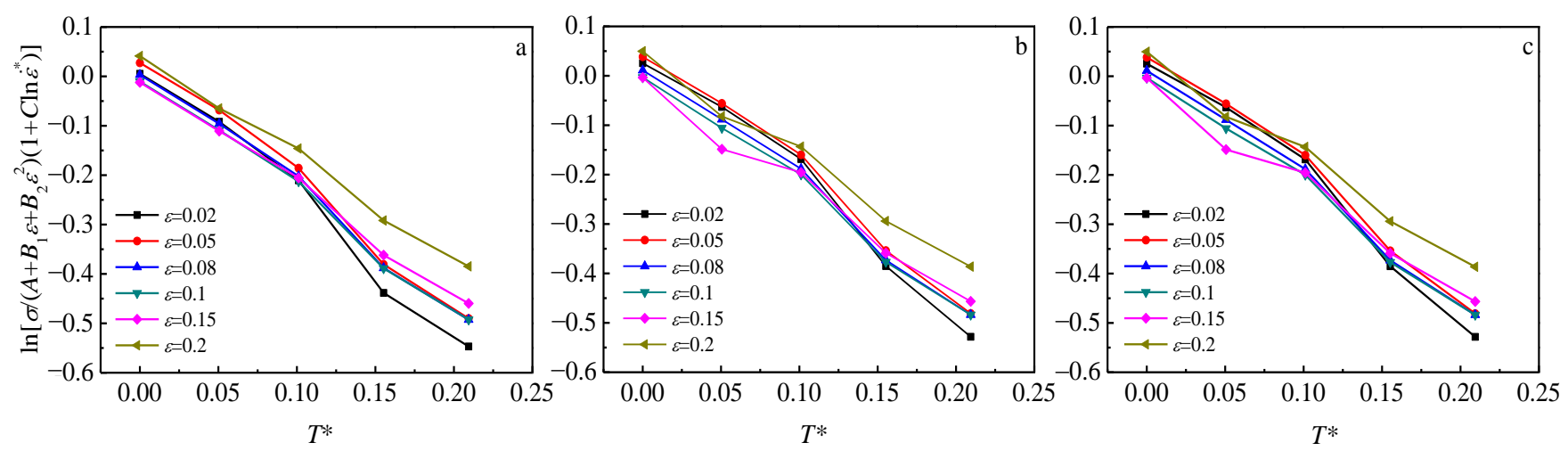

Fig.10 Relationship between $\ln \left[\frac{\sigma}{\left(A+B_{1} \varepsilon+B_{2} \varepsilon^{2}\right)\left(1+C \ln \dot{\varepsilon}^{*}\right)}\right]$ and $T^{*}:$ (a) $\dot{\varepsilon}=0.00005 \mathrm{~s}^{-1}$, (b) $\dot{\varepsilon}=0.0005 \mathrm{~s}^{-1}$, and (c) $\dot{\varepsilon}=0.005 \mathrm{~s}^{-1}$

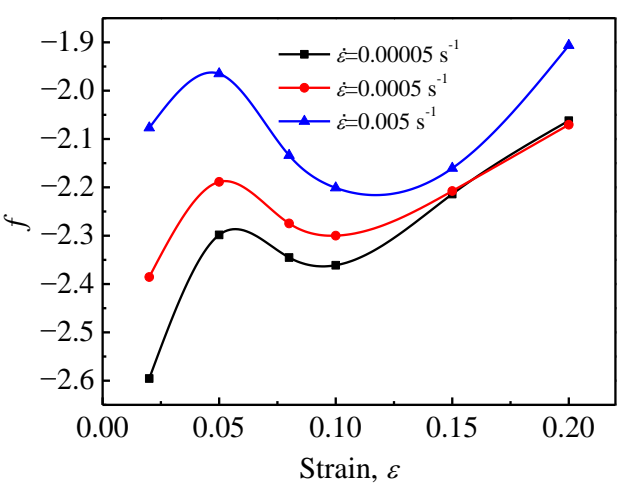

Fig.11 Relationship between $f$ and $\varepsilon$

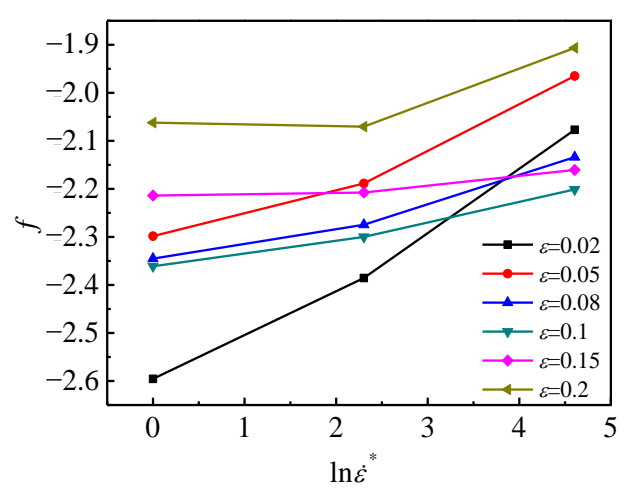

Fig.12 Relationship between $f$ and $\ln \dot{\varepsilon}^{*}$

$a_{1}, a_{2}, a_{3}, a_{4}, a_{5}, a_{6}, a_{7}$ can be obtained. Thus, $f$ is expressed as: $\begin{aligned} f= & \left(-92.9631+1031.585 \varepsilon-16558.8 \varepsilon^{2}+104130.6 \varepsilon^{3}-\right. \\ & \left.216844 \varepsilon^{4}\right)\left(-0.000643 \ln \dot{\varepsilon}^{*}+0.032566\right)\end{aligned}$

The modified JC model is finally expressed as follows:

$$
\left\{\begin{aligned}
\sigma= & \left(238.5783+1605.288 \varepsilon-4667.36 \varepsilon^{2}\right)\left(1+0.025588 \ln \dot{\varepsilon}^{*}\right) \exp f T^{*} \\
f= & \left(-92.9631+1031.585 \varepsilon-16558.8 \varepsilon^{2}+104130.6 \varepsilon^{3}\right. \\
& \left.-216844 \varepsilon^{4}\right)\left(-0.000643 \ln \dot{\varepsilon}^{*}+0.032566\right)
\end{aligned}\right.
$$

\subsection{Comparison between the original JC and modified JC model}

In order to investigate the prominence of the modified JC model, comparisons between experimental data and the flow stress predicted by original JC model and that by the modified JC model at different temperatures and strain rates are shown in Fig.13. From Fig.13, some conclusions can be obtained:

(1) When the deformation temperature $283 \mathrm{~K}$ is the reference temperature and strain rate is in the range of $0.00005 \sim 0.0005 \mathrm{~s}^{-1}$, both original JC model and the modified JC model can describe the flow stress of CP-Ti well. However, as the strain rate increases to $0.005 \mathrm{~s}^{-1}$, much deviation appears between the experimental value and the value predicted by original JC model, as shown in Fig.13b.

(2) When the deformation temperature is higher than the reference temperature $(283 \mathrm{~K})$, the flow stress predicted by original JC model is much higher than the experimental value and it seems like that the higher the deformation temperature is, the more deviation appears between experimental value and the value predicted by original JC model, as shown in Fig.13c 13f.

(3) At the temperature of $283 \sim 573 \mathrm{~K}$ and strain rate of $0.00005 \sim 0.005 \mathrm{~s}^{-1}$, a good agreement between the experimental data and the predicted data of MJC model is obtained, which indicate that the modified JC model can be used to precisely predict the flow stress for CP-Ti.

What is more, the performance of the original $\mathrm{JC}(\mathrm{OJC})$ and the modified JC model (MJC) are further evaluated by statistical analysis of the average absolute error. As the deformation temperature increases, the average absolute error of OJC is getting higher and the highest error of OJC is $34.16 \%$. While, the average absolute error of MJC is much lower, the highest error of MJC is $6.02 \%$ and most of the average absolute error of $\mathrm{MJC}$ are in the range of approximately $1 \% \sim 4 \%$. Therefore, the flow stress of CP-Ti is fitted 

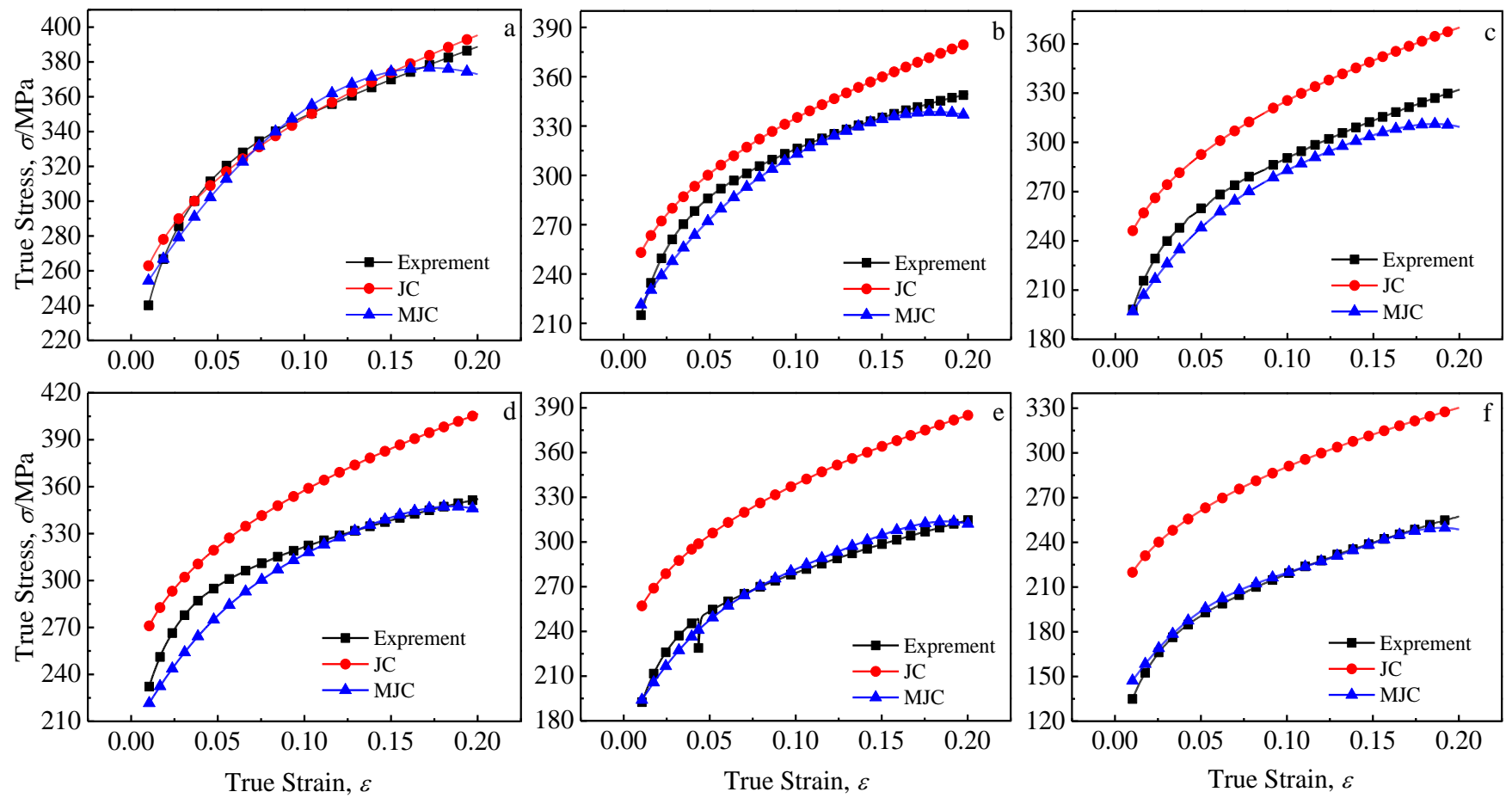

Fig.13 Comparisons between the experimental value and the value predicted by original JC model and modified JC model:

(a) $283 \mathrm{~K}, 0.00005 \mathrm{~s}^{-1}$; (b) $283 \mathrm{~K}, 0.005 \mathrm{~s}^{-1}$; (c) $353 \mathrm{~K}, 0.005 \mathrm{~s}^{-1}$; (d) $423 \mathrm{~K}, 0.005 \mathrm{~s}^{-1}$; (e) $498 \mathrm{~K}, 0.005 \mathrm{~s}^{-1}$;

(f) $573 \mathrm{~K}, 0.001 \mathrm{~s}^{-1}$

much better by the modified JC model compared with the original JC model.

\section{Conclusions}

1) The quantitative relationship between the strength coefficient $(K)$, the strain hardening exponent $(n)$, the strain rate sensitivity exponent $(m)$ in Fields-Backofen equation and the corresponding deformation temperature were investigated.

2) A modified Johnson-Cook model was proposed to describe the plastic flow stress of CP-Ti by considering the coupled effects of strain and temperature, stain rate and temperature. Compared with the experimental data, the modified Johnson-Cook model shows a more precise performance than the original Johnson-Cook model.

3) Both the modified Johnson-Cook model and the updated Fields-Backofen equation can give a reasonable description of flow stress for CP-Ti. The accuracy of updated Fields-Backofen equation is lower than the modified JC model, but the amount of parameters in FB is less and the determination of parameters in FB is simple. Therefore, the updated Fields-Backofen equation is preponderant when the the requirement to constitutive model accuracy is not very high.

\section{References}

1 Xu G D, Wang G S. Chinese Journal of Rare Metals[J], 2009,

\section{3(6): 903 (in Chinese)}

2 Zeng Z, Jonsson S, Zhang Y. Materials Science and Engineering $A[\mathrm{~J}], 2009,505: 116$

3 Zeng Z, Zhang Y, Jonsson S. Materials and Design[J], 2009, 30 : 3105

4 Sajadifar S V, Yapici G G. Materials and Design[J], 2014, 53: 749

5 Peng J, Zhou C Y, Dai Q et al. Materials and Design[J], 2013, 50: 968

6 Takuda H, Morishita T, Kinoshita T et al. Journal of Materials Process Technology[J], 2005, 164: 1258

7 Quan G Z, Tong Y, Luo G et al. Computational Materials Science [J], 2010, 50: 167

8 Zhang X H. Experimental and Numerical Study of Magnesium Alloy during Hot Working Process[D]. Shanghai: Shanghai Jiaotong University, 2003 (in Chinese)

9 Chun Y B, Davies C H J. Materials Science and Engineering $A[\mathrm{~J}], 2011,528: 5713$

10 Kubin L P, Styczynski A, Estrin Y. Scripta Metallurgica et Materialia[J], 1992, 26: 1423

11 Neeraj T, Hou D H, Daehn G S. Acta Materialia[J], .2000, 48: 1225

12 Liu J M, Chou S S. Journal of Materials Process Technology[J], 1999, 95: 65

13 Lin Y C, Chen X M, Liu G. Materials Science and Engineering $A[\mathrm{~J}], 2010,527: 6980$ 
14 Song W D, Ning J G, Mao X N et al. Materials Science and Engineering $A[\mathrm{~J}], 2013,576: 280$
15 Wang Y, Zhou Y X, Xia Y M. Materials Science and Engineering $A[\mathrm{~J}], 2004,372: 186$

\title{
工业纯钛在中低温下的 Fields-Backofen 和改进型 Johnson-Cook 方程
}

\author{
常 乐, 周昌玉, 彭 剑, 李 建, 贺小华 \\ (南京工业大学, 江苏 南京 211816)
}

\begin{abstract}
摘 要: 通过单轴拉伸试验研究工业纯钛在 283 573 K 下应变速率范围为 $0.00005 \sim 0.005 \mathrm{~s}^{-1}$ 的流动应力行为, 确定工业纯钛应变速率敏 感性及应变强化指数随温度的定量变化。结果表明: 工业纯钛的应变速率敏感性在 283 423 K 不显著, 应变强化指数在 353 573 K 随温 度变化而增加。基于温度变化的修正型 Fields-Backofen 方程, 建立了能够描述工业纯钛塑性流动应力行为的数学模型。同时, 考虑应 变、应变速率及温度之间的相互作用, 对传统的 Johnson-Cook 方程进行改进。与传统的 Johnson-Cook 方程相比, 改进型的 Johnson-Cook 方程与实验结果吻合更好, 证明改进型 Johnson-Cook 方程预测工业纯钛塑性流动应力的精确性。

关键词: 工业纯钛; 拉伸变形; Fields-Backofen 方程; Johnson-Cook 方程
\end{abstract}

作者简介: 常 乐, 男, 1991 年生, 博士生, 南京工业大学机械与动力工程学院, 江苏 南京 211816, 电话: 025-58139951, E-mail: 294473642@qq.com 